\title{
Computer Network Assisted Teaching of College English Reading
}

\author{
http://dx.doi.org/10.3991/ijet.v11i08.6048 \\ Meng $\mathrm{Xu}^{1}$, Kang $\mathrm{Lv}^{2}$ and Xinwen $\mathrm{Bi}^{* 1}$ \\ ${ }^{1}$ Beihua University, Jilin, Fengman, China \\ ${ }^{2}$ Henan Institute of Education, Zhengzhou, Henan, China
}

\begin{abstract}
The use of modern science and technology related to teaching equipment has created a new mode of English reading, and the network environment has opened a new world for English reading. In this paper, the advantages, feasibility, operation and current problems of computer network assisted teaching of English reading are analyzed and discussed.
\end{abstract}

Index Terms-computer network; college English reading; assistant teaching; teaching character.

\section{INTRODUCTION}

The emergence and popularization of computers and the Internet, the latest development of modern multimedia technology and the advent and application of various kinds of editing software, as well as valuable experience gained in multimedia and computer assisted language teaching globally, all provide a superior objective environment and convenient conditions for the reform of foreign language teaching This brings the teaching and learning of English reading enter into a scientific and modern network environment, forming a new teaching mode, transforming the traditional teaching model, introducing "edutainment" and "Entertainment in English" and greatly improving teaching efficiency [1].

\section{ENGLISH READING UNDER THE COMPUTER NETWORK ENVIRONMENT}

As English is a tool to understand and know the world, reading plays the important role as a bridge. In fact, whether the information is online or in a book, it requires a high reading ability to obtain it. English reading ability is not only the ability to master the basic knowledge of the language including words and phrases, but also the ability of language application which is even more important.

Language scholars globally believe that reading is a form of written communication and it is a form of communication between the author and readers. Chunyu Yongqi thinks that reading is also a process of information processing, which means to take in the information from the author in the article as much as possible. It is a positive and active way to get information. He also pointed out that "reading is also a screening process" [1]. Reading skill depends on the effect of the interaction between the reader's language knowledge as well as knowledge of the world. Goodman thinks that in the process of reading, readers are in a "guessing game" and it is a complex psychological activity. The purpose of reading is to gain and remember knowledge through understanding. Mr. Xu Guozhang said "do not put the purpose of reading on the improvement of English. Reading absorbs the knowledge first. The language is naturally absorbed in the process of absorbing the knowledge." [3] Therefore, reading is to gain and absorb knowledge. The purpose is to gain and remember knowledge in the understanding process. The traditional teaching of reading depends on the textbook and the teacher's explanation and demonstration, which is time-consuming, laborious, and tedious. Although it has its merits, as time passes students develop passive learning attitudes and learning methods in foreign language learning, and there will be the lack of enthusiasm, initiative and creativity. Students will feel bored and therefor uninterested in such an environment. As a result, a large portion of students have not been able to master the reading skills by graduation and do not have the ability to read independently, as shown as Figure 1. Therefore, simply using the traditional teaching mode and means cannot meet the needs of the new situation. The futurist scientist Naisbitt also pointed out that: "After entering the information age of the whole human society, people's ways of production and life mainly depend on knowledge and information. The knowledge productivity which is formed by them has become the key factor of productivity, competitiveness and economic development. And this knowledge productivity could only be obtained relying on reading." [5].

Abundant reading is the most convenient and practical way to learn English in non-first language environment. Nowadays, the reading environment is dominated by the computer, Internet and multimedia platforms. People can have access to all the knowledge in the world without going outside, finish a variety of complex work sitting in the front of the screen without going to the library and potentially read tens of thousands books without travelling for thousands of miles [6].

\section{Advantages Of COMPUter Network Assisted TEACHING OF ENGLISH}

Computer assisted language teaching is not a new idea. It has been used for quite a long time in language teaching. Computer assisted language teaching which is based on computer assisted instruction (CAI), began in the 60's in the United States. It has become an essential method of modern foreign language teaching, being able to make up for the deficiencies of traditional teaching. The learning environment has been moved from the traditional classroom equipped with a blackboard and the teacher's voice, to the multimedia computer classroom, the interactive language environment with good vision and auditory capabilities.

The application of modern science and technology to teaching equipment has created a new mode of English reading learning and practicing, and the network environment has opened up a new world for English reading. Network language is synchronized with the actual devel- 
opment of language, multimedia technology used by computer software creates strong interest with its userers. It can also turn the static to dynamic by controlling and combining digital images, sound, text and animation randomly. It is suitable for teachers to use with different teaching methods according to different teaching objects, achieving a student-centered situational teaching [8]. The traditional teacher-centered classroom teaching methods will be shifted to the personalized network based teaching with the students as the center. The Internet provides supports for many aspects of the teaching of Englishthat English teachers can use, as shown in Figure 2.

\section{A. Rich English resources are the biggest advantage of the network}

Online English resources are inexhaustible, free-shared and an ocean of information. In the course of teaching, teachers could download the language materials from the Internet, screen and edit and guide the students' reading. Students can also make their own online testing and browsing, expand their knowledge and deepen their understanding of the contents of the study, even make a preliminary study on a special subject using network resources. In this way, students' reading is no longer confined to a text in a textbook, but are exposed to living language material closer to real life.

\section{$B$. Internet provides advanced tools for reading practice}

The traditional English reading tool is an EnglishChinese dictionary. Not only is carrying a thick and heavy dictionary inconvenient, the more important issue is that using a paper dictionary is time consuming and often yields little meaningful knowledge. One reason is that the dictionary has a limited capacity. Another is that new words are not included because paper dictionaries seldom publish new editions. However, on the Internet, the needed content can be found by landing a remote server, such as the connection of an online library catalogue. At the same time our own problems or ideas can be sent to experts via email for consultation and exchange. In addition, chat rooms and BBS, etc. can also be used as a tool for reading and communication. Other tools such as translation tools, note taking tools and tools for accessing information effectively help students carry out reading, learning and practice.

\section{Strong interaction}

It could support teachers to tutor and help students in a synchronous or asynchronous way. During traditional reading, readers could not arbitrarily control the literature auxiliary tools such as the recorder and it is only passive listening and reading. In the multimedia computer classroom, the listener can use the mouse to arbitrarily adjust the sound, words and pictures and control their own learning speed. Through the Internet, users can have access to the information of global libraries, and make effective distance learning possible. Through the campus network, they can listen to and read the news of that day, chat with foreign friends directly and learn the idiomatic English in a real, not simulated network environment [10].

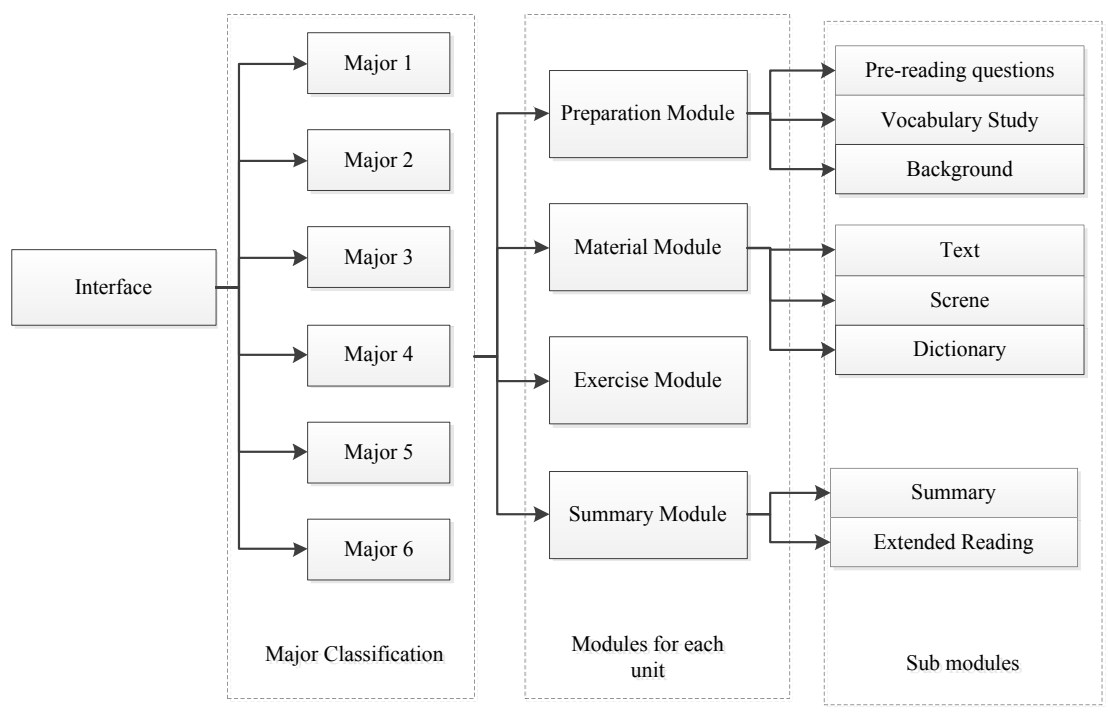

Figure 1. Software structure

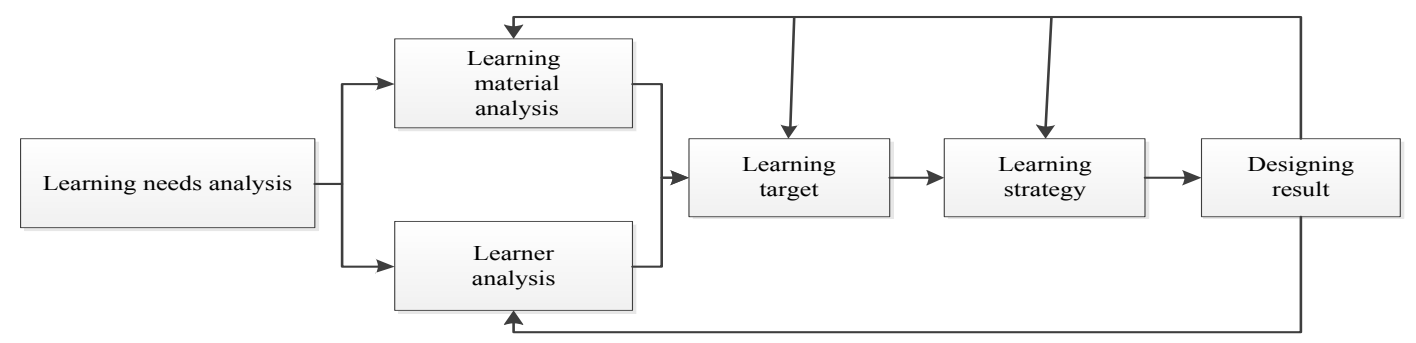

Figure 2. Design of teaching software 


\section{Improving learners' English reading skills}

Searching for information on the Internet requires a certain logical skill. First of all, much relevant information needs to be browsed to get the exact information. Secondly, the information needs to be refined to make the right judgment. After obtaining a number of valuable pieces of information, the integration work should be done to make sure that the information on the Internet is complete and logical. The effort of Internet users to get online information is also an effort to practice reading skills and strategies [12]. After searching the Internet dozens of times or hundreds of times, reading abilities of learners have been developed either from top down or from bottom up, as shown in Figure 3.

\section{How To SELEct Materials}

\section{A. English language materials should be able to arouse interest in reading}

Language materials should be fresh, changing, and above all, interesting to the reader. Only such reading materials are able to enable readers to store information from short-term memory into long-term memory, and will be enjoyable to engage in. Therefore, the selection and optimization of language materials play an important role in English reading. Traditional reading teaching materials are chosen by editors and teachers according to the teaching outline with purposes and goals. The use cycle is long, but the interaction is weak. The explanation of language materials is mainly organized in the classroom according to a certain teaching method. Students complete the reading training in such a language environment and then go on to a variety of English tests. This kind of reading teaching method only focuses on language form training and the cognitive function is higher than the actual use of language. What it trains are the "the examination experts", which is a student whose only goal is to score high on tests and exams rather than thinking of study as being for the sake of gaining knowledge. Guessing the meaning of words, grammar analysis and analysis of the structure of the text are the basis for the acquisition of language knowledge. But they are not able to develop the ability to actually use language in a real-life setting. Reading ability is not only the ability to comprehend what is being read. The real reading ability should be the conscious or unconscious input - perception - comprehension - appreciation transfer - of a large number of language materials.

Therefore, the selection of topics should be extensive, which covers social, political, economic, cultural and other aspects of English speaking countries. The content should be new, paying attention to including papers reflecting the social progress and the development of science and technology in recent years. Attention should be paid to interests and the style should be diverse, such as the introduction of common sense of life with the combination of text and graphic materials, fable and fairy tale materials, newspapers, other forms of news, advertising, music lyrics, web materials, reading materials of international culture and science and technology materials in both Chinese and English. The source of materials should be preferred to American English or British English to ensure that materials which students encounter should be authentic English with communicative meaning. The extensive reading of language materials which are closely related to social life and culture of today's English speak- ing countries with lively style and vivid contents, not only enlarges students' vocabulary and knowledge, but also promotes students' listening, speaking and writing abilities.

\section{B. Timeliness of language materials}

In today's rapidly developing world of the IT industry, the Internet better reflects the fact that international politics, economy, culture and life are all closely related. Therefore, the network language is synchronous with the actual language. Only by learning the most realistic language as it is actually used can one understand and assimilate into society. Most newspapers and other kinds of articles convey timely information that can be updated step by step as time passes, which makes these forms a good choice for reading material. Editing and publishing new editions of printed teaching material is only done periodically, so it takes a very long time to get new or fresh material to the readers. However, through the Internet students can easily read the day's British and American electronic newspapers and magazines, its content being in the wake of current affairs, closely related to reality, is often the current hot issues with deep analysis and discussion, so that the students can access the latest information and grasp the pulse of the times. In learning a language, integrating Internet network auxiliary teaching solves the problem of language learning and application, while at the same time being very practical.

\section{READING TRAINING}

\section{A. Training of fast English reading on the computer}

Fast English reading on the computer could be mastered through purposeful teaching and training. This new teaching of English reading has just started with the information age. In foreign language teaching, we can proceed from the following aspects:

(1) In the training and teaching of fast English reading, readers should clearly know the purpose of reading. They should also cultivate skills of predicting contents, grasping the main idea, grasping the specific details, guessing the meaning of words according to the context, inferring the implied meaning and identifying the transition section etc. Furthermore, the reader should be trained to use the editing skills of the computer to mark, make notes, outline, highlight, insert comments, etc., as well as learning the use of hyperlink when reading on the computer, as shown in Figure 4-7.

(2) Reading speed and reading comprehension should be kept at a certain ratio determined by tests. According to experience, if the ideal rate of reading comprehension is $70 \%$, the reading speed is appropriate. If it is between $80 \%-100 \%$, readers should increase their reading speed to lower the comprehension to $70 \%$. If the rate of reading comprehension is only $50 \%$, then the original reading speed should be lowered to improve the comprehension rate.

(3) To master the skimming reading method and scanning reading method

Scanning reading method is a reading method used to quickly find specific information. This method can save time when looking for a specific topic, fact or data. The reading method is especially suitable for reading English information on a computer network. Three methods could be adopted in teaching. First, readers should remember the 
PAPER

COMPuTER Network Assisted TEACHING OF COLLEGE ENGLiSH READING

question to answer or the information to search before reading. Second, readers should make use of the information in a list, index or online home page to guess the area in which the information is likely to appear. Third, readers should keep in mind the words that are relevant to the information needed. The full use of these reading skills could help readers to find the useful information in the English materials on the computer or computer network quickly.

\section{B. Network assisted traditional teaching of reading}

Printed materials could be combined with the network. Although the contents of teaching materials might be outdated, the basic knowledge and the words are what beginners should master. Based on the teaching materials, diversification of the theme choice is to be achieved. Relevant web sites are searched on the Internet according to the contents of the article in the teaching materials, or related teaching materials can be downloaded from various websites. The article and the background material are analyzed and stored on the server as auxiliary materials when students learning the text content of the same subject. Students are guided to use extra-curricular materials to better understand the author's point of view, text structure, the central idea and the background knowledge of the text, thus attaining a more comprehensive understanding of the content of the article. For example, when learning Lesson Five, the text related to HIV/AIDS, of Reading Course of British and American Newspapers and Periodicals, edited by Danu Yawn, teachers find websites related to AIDS in advance and send to them to students' mailboxes. Students make their own choices to search the Internet according to the websites provided by teachers. Therefore, students will be very easily understand the author's point of view, text content and background knowledge.

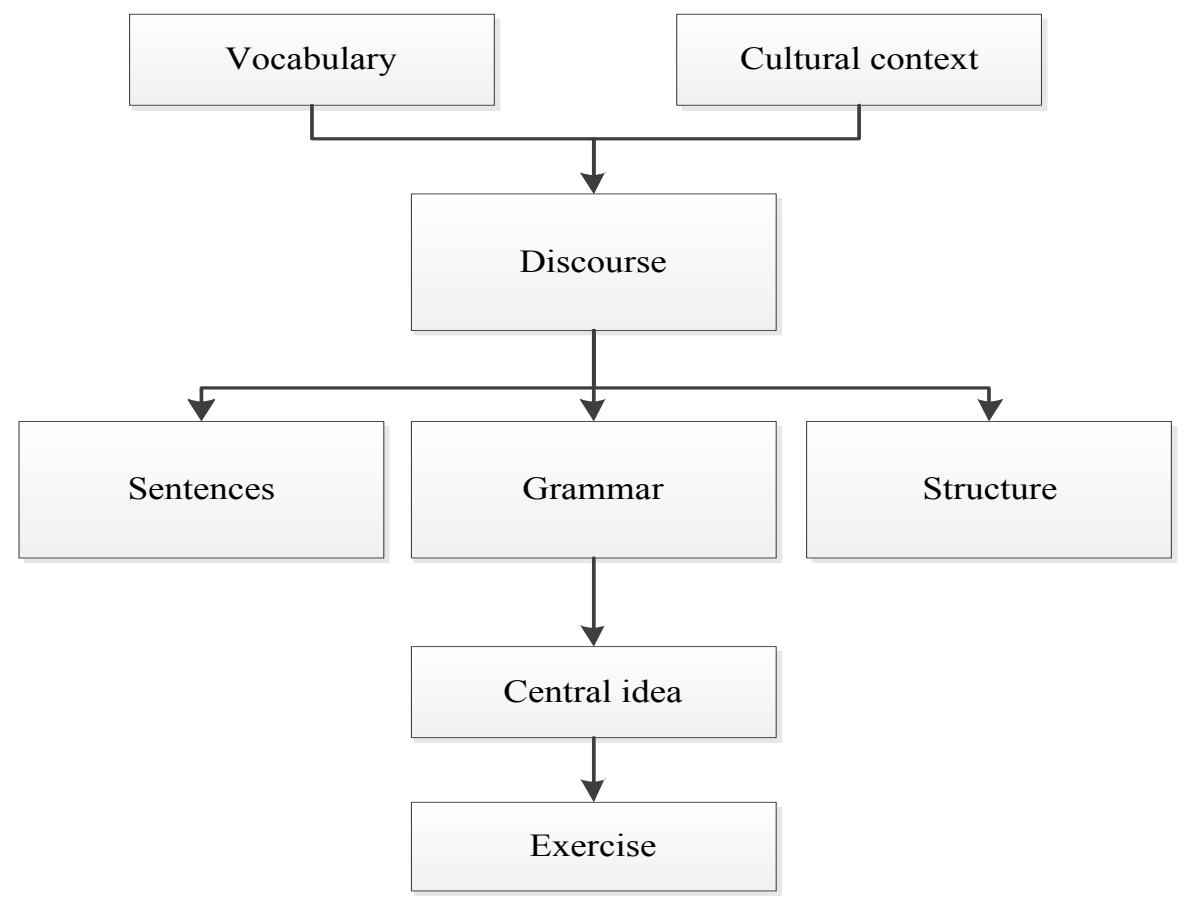

Figure 3. Leaning content organization

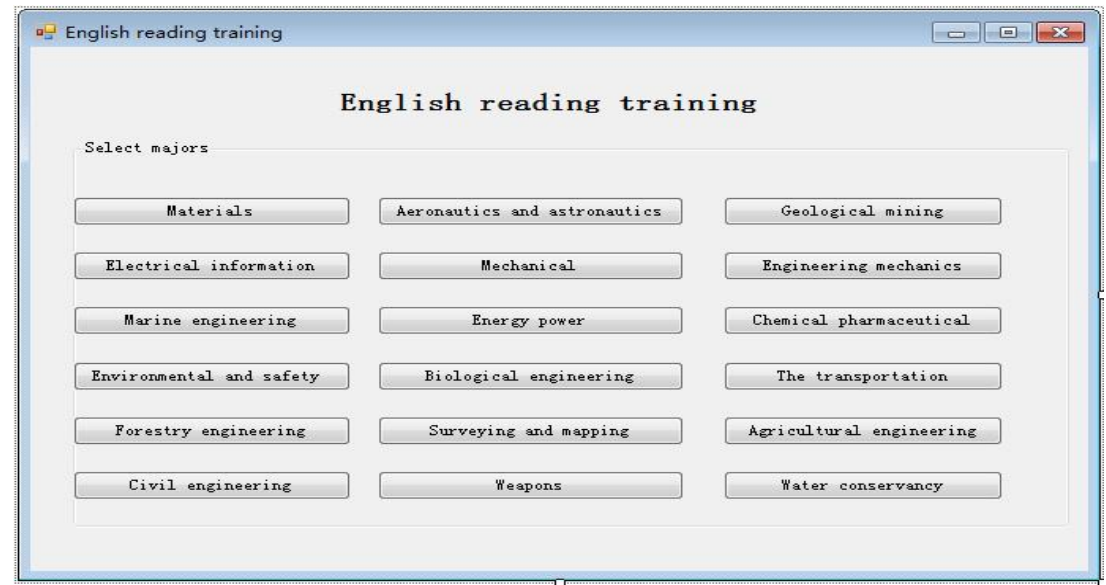

Figure 4. English reading training software 
PAPER

COMPuter Network Assisted TEACHING OF College ENGLish REAding

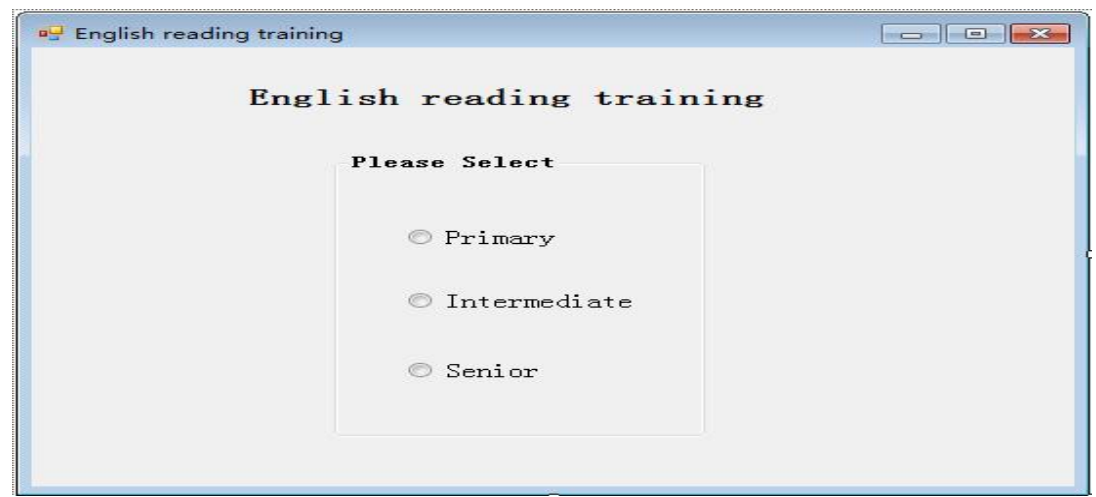

Figure 5. Reading training selection interface

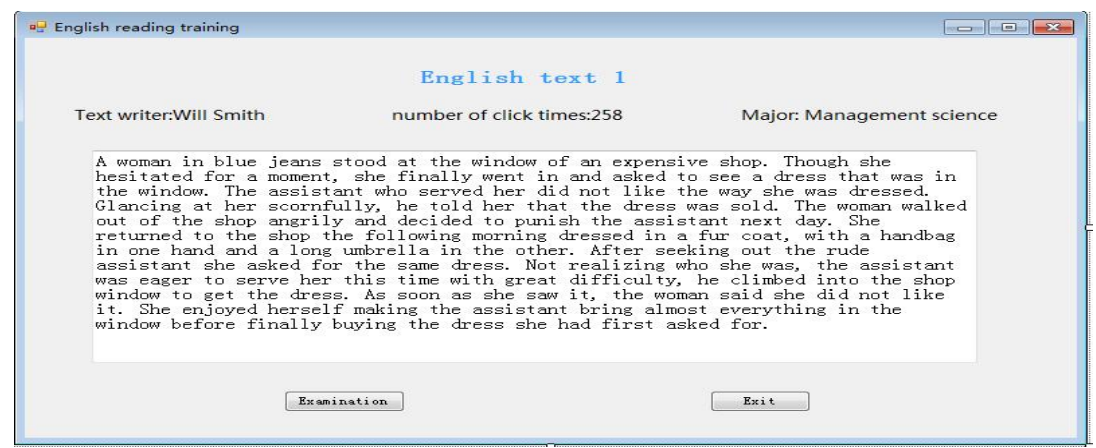

Figure 6. English training interface

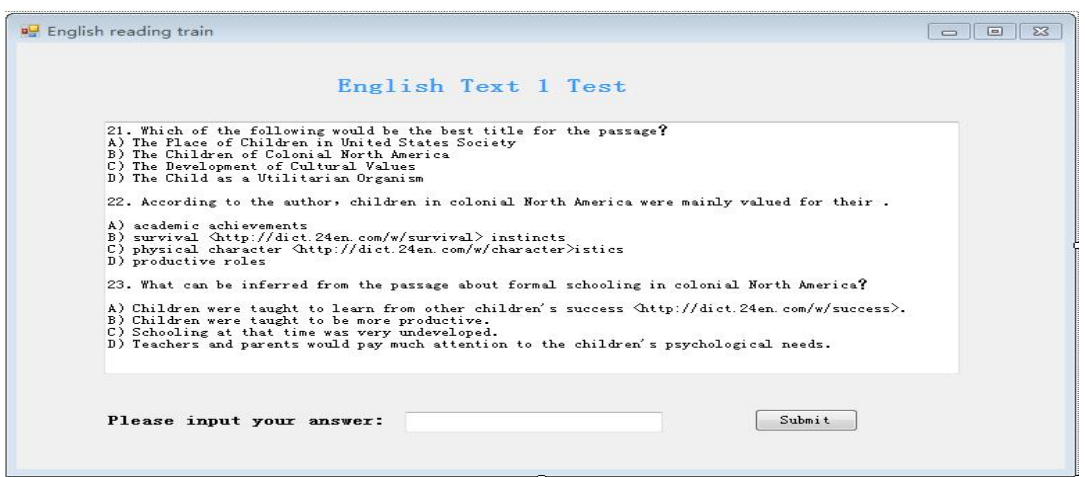

Figure 7. Examination for English reading interface

\section{The Purpose, Form ANd EFFECT Of TEACHING ASSISTED BY COMPUTER NETWORK}

English teaching in college assisted by a computer network has transformed the traditional teaching methods and modes with the purpose that students are actually playing the leading roles and teachers are the facilitators and instructors. In the teaching assisted by a network, after the teachers assign the tasks, students will actively enter the websites and distribute the study time according to their learning methods and customs. They may choose to spend more time on material that they feel is more difficult and less time on the material that they feel is too easy for them, so that they are able to greatly enhance the learning efficiency. Additionally, students can learn according to their interests. Rich websites and a large amount of learning material will greatly stimulate their learning interests.

To some extent, teaching assisted by a computer network has realized the one-on-one ideal of teaching. The computer is just like a teacher faced by students who are able to communicate and interact with it any time they want with no shyness or anxiety. Linguistic studies show that anxiety is one of biggest hindering factors in learning foreign languages. Chinese students are known for being shy who are not active in expressing their thoughts and ideas in class, especially in situations where there are many people present. The teaching assisted by a computer network has solved this problem. We discover that teaching assisted by a computer network is able to enhance the listening and speaking ability of students to a large extent. In the final exams, the performance of students who participated in classes assisted by a computer network is significantly improved in terms of listening and speaking ability.

Additionally, most students feel that they do not get sufficient chances to practice oral English with teachers and they also dislike the traditional method of lecturing in which teachers are playing the only role. They wish that teachers are able to have one-on-one interaction with students. In the teaching assisted by a computer network, teachers will assign some self-learning tasks for students to complete before classes, which resultin in more class 
PAPER

time left for them to discuss in groups. In discussion, teachers encourage students to use new knowledge and actively take part in oral English practice. But they feel that the time to exercise is not enough and the time for an individual student to practice is even less.

To sum up, although there are still some problems with teaching assisted by a computer network, it is still overall effective.

\section{A. The role of English teachers in classes and the challenges they confront}

Currently, although teaching assisted by a computer network has been utilized, the percentage of this mode being used in all the teaching activities is only approximately $50 \%$. That is to say, students spend half of their time studying in computer rooms and the other half in classrooms where teachers deliver classes orally and students are mostly passive. However, this process triggers teachers to feel that they do not know what to deliver to students with a feeling that "robots are replacing people", as the material in the network is so rich and so comprehensive in term of the background information of textbooks and the language points, grammar structure, the corresponding consolidation exercises in the articles.

From this author's perspective, the teaching assisted by a computer network has actually presented a great challenge to teachers, at the same time it is also a stimulus that encourages teachers seek new teaching methods, new supplementary material for teaching and review the articles that students have basically mastered from new perspectives so as to effectively conduct English teaching activities. Lessons conducted in the classroom which seems to always be repetitive, can actually be filled with inspiration and challenges. Teachers should not only solve the problems students encounter from self-learning on the Internet, but also have an in-depth understanding of the articles the students are reading and try every possible means to attract, inspire, and encourage students.

Certainly, in classes, dictation of teachers is actually the way to solve the problems students encounter in material from the Internet. To some extent, teaching in classes is an extension of teaching assisted by a network, but, it is not simply an extension of time, but the sublimation of the content. If the content is sublimated in this way, teachers have succeeded and students will feel satisfied and the teaching will be more engaging. However, to reach the target is never easy. Teachers need to spend more time preparing classes and referring to more relevant materials so that they are able to be qualified to accomplish the idea that "to give others a drop of water, they must first have a bucket of water". Therefore, teachers are required to enhance their qualification and professionalism and research on new teaching theory and methods. Only in this way can they overcome the new challenges.

B. Coordinate the relationship between teaching in classrooms and teaching assisted by a computer network

The college English teaching assisted by a computer network plays a significant role in cultivating the listening and speaking abilities of students and its role will continuously become increasingly important in future teaching activities. But, form this author's perspective, the leading role in college English teaching is still personnel, that is to say the role of teachers should cannot be ignored. Nega- tive consequences will occur if the principle is not heeded. No matter how advanced the technology is or how developed the human society becomes, languages will still be taught by people.

Language is only possessed by humans, a subject of which belongs to social sciences. Although machines are a great help for mankind, the leading role in the world is still played by human-to-human interaction. The words and deeds and personal charm of teachers will have some positive effect on students. The teachers who are experienced know exactly the difficulties confronted by students in the process of English study and they know how to help students to solve them so that students will be persistently intrigued by English and discover better methods of how to learn it. In classes, the words and deeds, gestures and hand moves, rich body language facial expressions, and tone of voice will all have a subtle influence on English learners. Additionally, teachers are also able to arrange varied teaching activities of foreign language so as to create a class atmosphere that encourages students to study, which can never be replaced by a computer network.

All in all, there is no doubt that college English teaching assisted by a computer network has a positive effect on college English teaching with preliminary effectiveness being manifested. This author believes that for future English teaching activities, teaching assisted by a computer network will play a larger role, and the college English teachers will become accustomed to this new teaching mode. But, English teaching assisted by a computer network plays only a supplemtary role which can never replace the role of teachers. Therefore, college English teachers must adjust the relationship between man and machines so that they can deliver classes in a more effective manner while not just depending on web-based courseware.

\section{CONSTRUCTION}

The application of computer network supported teaching is of great practical significance to China's English education. It could make up for the deficiencies in aspects of English teachers, the language learning environment and teaching resources etc., and mutually complement and promote teaching along with traditional teaching methods. China's English education has been plagued by a shortage of teaching staff. In terms of college English, public English teaching belongs to the category of basic teaching. Not much attention is paid to college English by the school and the treatment of most schools is poor, which makes it difficult to attract talented people. Under the traditional teaching mode, the teaching of English should be in small classes and requires much manpower. To solve this problem, the school must pay more attention to college English teaching, strengthen the construction of English teaching staff and improve their treatment of these staff. At the same time, we could also implement some new measures, such as reforming teaching by introducing the computer network technology into English teaching and making the computer partially replace English teachers. The corresponding network based courseware must be developed for teaching contents of English reading, vocabulary, grammar, listening and so on which requires much repeated practice, giving full play to the advantages of human computer-interaction in the new technology, making the interactive feedback of the computer replace 
the repetitive work of teachers, making the students learn on their own following the computer's guidance and stimulating their enthusiasm, which could make up for the shortage of teachers to a certain extent.

Network teaching is something new to China and it needs our efforts to grow and develop. We believe that with the development of information technology, network teaching under the support of modern information technology will become an effective teaching mode in English education and eventually become widely accepted. English teaching in the network environment is a new field of English teaching. As college teachers, we should make our own contribution in this regard to support it and help its development.

\section{REFERENCES}

[1] G. Eason, B. Noble, and I. N. Sneddon, "On certain integrals of Lipschitz-Hankel type involving products of Bessel functions," Phil. Trans. Roy. Soc. London, vol. A247, pp. 529-551, April 1955. http://dx.doi.org/10.1098/rsta.1955.0005

[2] J. Clerk Maxwell, "A Treatise on Electricity and Magnetism," $3^{\text {rd }}$ ed., vol. 2. Oxford: Clarendon, 1892, pp.68-73.

[3] I. S. Jacobs and C. P. Bean, "Fine particles, thin films and exchange anisotropy," in Magnetism, vol. III, G. T. Rado and H. Suhl, Eds. New York: Academic, 1963, pp. 271-350.

[4] K. Elissa, "Title of paper if known," unpublished.

[5] R. Nicole, "Title of paper with only first word capitalized", $J$. Name Stand. Abbrev., in press.

[6] Y. Yorozu, M. Hirano, K. Oka, and Y. Tagawa, "Electron spectroscopy studies on magneto-optical media and plastic substrate interface," IEEE Transl. J. Magn. Japan, vol. 2, pp. 740-741, August 1987 [Digests $9^{\text {th }}$ Annual Conf. Magnetics Japan, p. 301, 1982]. http://dx.doi.org/10.1109/TJMJ.1987.4549593

[7] M. Young, The Technical Writer's Handbook. Mill Valley, CA: University Science, 1989.

[8] X.H. Chen, "The research on English autonomous learning monitoring theory and application in the network environment". $A p$ plied Mechanics and Materials, Vol.12, pp.6079-6082, 2014. http://dx.doi.org/10.4028/www.scientific.net/AMM.644-650.6079

[9] S.F. Han, S. Miao, "On college English teaching of writing in the network environment”. 2011 International Conference on Multimedia Technology, ICMT 2011, pp.588-590. http://dx.doi.org/10.1109/ICMT.2011.6002176

[10] S. Li, "Survey research on college students' English learning anxiety in the computer network environment". ICCSE 2011-6th International Conference on Computer Science and Education, Vol.36, pp.1010-1012, 2011.

[11] J. Song, "The English teaching model of cooperative learning in the network environment in higher vocational education". Communications in Computer and Information Science, Vol.218, pp.100-104, 2011. http://dx.doi.org/10.1007/978-3-642-23357919

[12] Q.L. Sun, "Information under the network environment using computer information security technology". Proceedings-2015 International Conference on Intelligent Transportation, ICITBS 2015, pp.474-477. http://dx.doi.org/10.1109/icitbs.2015.122

[13] M.Q. Xu, "The research on out-of-class autonomous English learning in computer-and network-assisted environment". Advances in Intelligent and Soft Computing, Vol. 36, pp. 453-459, 2011. http://dx.doi.org/10.1007/978-3-642-24775-0 71
[14] D.L. Yang, Zheng, H., "Research on the framework of new college English teaching mode integrating cooperative and autonomous learning in the network multimedia environment". ICETC 2010-2010 2nd International Conference on Education Technology and Computer, Vol.3, pp. 3256-3259, 2010.

[15] J. Zhou, Chen, X.H., "Analysis and simulation of computer virus propagation models in the network environment". Advanced Materials Research, Vol. 204, pp.433-436, 2014.

[16] P. Zhang, "Analysis on the development of computer basic education under network environment". TEIN 2012-2012 3rd International Conference on Telecommunication and Information, Vol.11, pp. 137-141, 2012.

[17] S. Li, "Multimedia computer assisted instruction in college English teaching," Proceedings-4th International Conference on Computational and Information Sciences, ICCIS 2012, pp. 754757.

[18] B. Shi, "Empirical research on feasibility and effect of computeraided College English teaching model," Proceedings-2009 International Conference on Information Engineering and Computer Science, ICIECS 2009, pp. 258-261. http://dx.doi.org/10.1109/ iciecs.2009.5362868

[19] R. Sun, "Analysis of teacher role in computer-based English teaching," Communications in Computer and Information Science, Vol. 267, pp. 458-463, August 2012. http://dx.doi.org/10.1007/ 978-3-642-29084-8_71

[20] X. Tang, "Integrating computer technologies into College English Teaching in China. 2010 International Conference on E-Health Networking," Digital Ecosystems and Technologies, EDT 2010, pp. 371-374.

\section{AUTHORS}

Meng Xu received his Bachelor's degree in Computer Science and Technology (2002) and Master in computer science and Technology (2013). Now he is the lecturer in the Institute of information technology and communication, Beihua University. His current research interests include computer application and computer teaching reform (e-mail: 3066567@qq.com).

Kang Lv received his Bachelor's degree in Computer Science and Technology Specialty (2004) and Master of Science in Computer Engineering Technology (2008). Now $\mathrm{He}$ is the lecturer of computer Department, Henan Institute of Education of China. His current research interests include different aspects of Network engineering and Data mining. (e-mail: 24295376@163.com).

Xinwen Bi is a master of computer application (2011). Now, she is a lecturer in the Institute of information technology and communication, and works in the Institute of information technology and communication, Beihua University. His current research direction is computer application. (e-mail: 52600613@qq.com).

This work was supported by exploration and practice of case teaching on professional application of "C language program design" (XJQN2016035); No.137 Science and Technology Planning Project Contract of the Education Department of Jilin Province (2015)" Research on fish model based on artificial life methods"; The development and resource construction of the Computer Science MOOC Platform. Submitted 16 July 2016. Published as resubmitted by the authors 28 August 2016. 